\title{
Structural Analysis of Mast of Special Rotary Drilling Rig for Transmission Line
}

\author{
Jian Qin ${ }^{1, a^{*}}$, Yimin Ma ${ }^{1, b}$, Yan Ding ${ }^{2, ~ c}$, Guangrui Tang ${ }^{1, d}$, Yu Sun ${ }^{3, ~ e ~, ~ a n d ~}$ \\ Jieming Bai ${ }^{1, f}$ \\ ${ }^{1}$ China Electric Power Research Institute, Beijing, 100055, China \\ ${ }^{2}$ Risk Management Department, China Everbright Bank, Beijing, 100032, China \\ ${ }^{3}$ Xuzhou Xugong Foundation Construction Machinery Co., Ltd, Xuzhou, China \\ aqinjian@epri.sgcc.com.cn, ${ }^{b}$ maym@epri.sgcc.com.cn, ${ }^{\mathrm{c}} 344577001 @ q q . c o m$, \\ dtangguangrui@epri.sgcc.com.cn, ${ }^{\mathrm{e}}$ sunyuhao2003@163.com, ${ }^{\mathrm{f}}$ 357911261@qq.com
}

Keywords: transmission line; rotary drilling rig; mast; lifting drill; structural analysis

Abstract. The mechanical model of mast of special rotary drilling rig for transmission line is established in this paper. The ultimate loads of mast of rotary drilling rig are designed for drilling condition and lifting drill condition, and the simulation of the mast is done under these typical working conditions. According to the analysis of the stress and deformation of mast, the weaknesses of mast is studied which can provide basis for the further optimization and improvement of mast structure.

\section{Introduction}

With the improvement of voltage levels for transmission line, the difficulty of foundation construction increases, so the security risk of manual excavation became more increasing. The special rotary drilling rig for transmission line has many advantages, such as small size, light weight, strong climbing ability, high security, good adaptability, etc, which can solve the problems of foundation construction in transmission line[1,2].

The maximum drilling diameter of special rotary drilling rig for transmission line XR180L is $2 \mathrm{~m}$, the maximum drilling depth is $20 \mathrm{~m}$, and the total weight is $45 \mathrm{t}$. The rig has heavy hydraulic retractable crawler which brings good travel performance. The chassis structure of rig has high strength so the stability of machine during working is well. So it is able to finish drilling-hole construction of foundation under harsh topographic condition in mountainous.

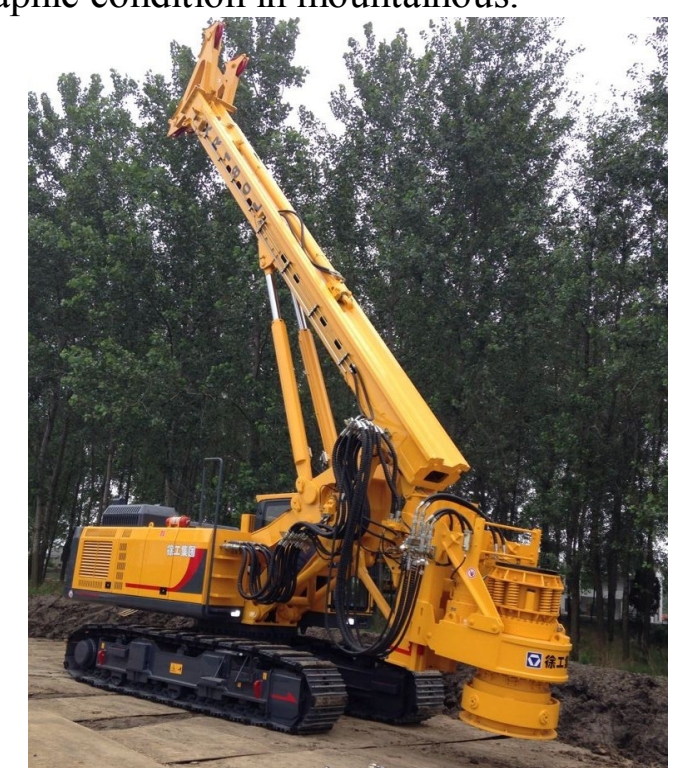

Fig. 1 XR180L special rotary drilling rig for transmission line

As one of key parts of rotary drilling rig, mast is a large steel structure with box section which loads all kinds of work forces. The stiffness of mast structure can influence directly the construction of rotary drilling rig. If the mast bends excessively, the working device such as drilling tool cannot move along 
the guide track of mast. Therefore, the study of the mechanical properties of rotary drilling rig mast is urgent and meaningful.

The function of rotary drilling rig mast is shown as the following several aspects.

(1) The mast structure supports the parts of rig, such as drilling tools, adjusting mechanism, pressure mechanism and so on.

(2) The mast provides orientation for drilling footage.

(3) The mast is the lifting arm of hoister.

At present, China has carried out extensive research of rotary drilling rig mast, but there are some deficiencies: (1)Due to the large mast structure and limited calculation resources, the mesh density of finite element model is small and the calculation accuracy is not high enough; (2)The position optimization of the mast hinge is not used the results of strength and stiffness of the mast structure; (3)The selection of limiting condition has lacks of adequate theoretical basis, and the affection of various postures of the rig parts to mast is not considered.

\section{Structure of Rig Mast}

Special rotary drilling rig for transmission line uses segmented folding mast. The mast is made of steel with box section and divided into three parts, respectively top mast (a goose head consists of two sets of the pulley mechanism), mid mast and a lower mast. The three parts of the mast unfold for meeting the drilling need in working state, and the top mast and lower mast can be fold back to the mid mast to reduce the transportation size of the complete machine in moving state.

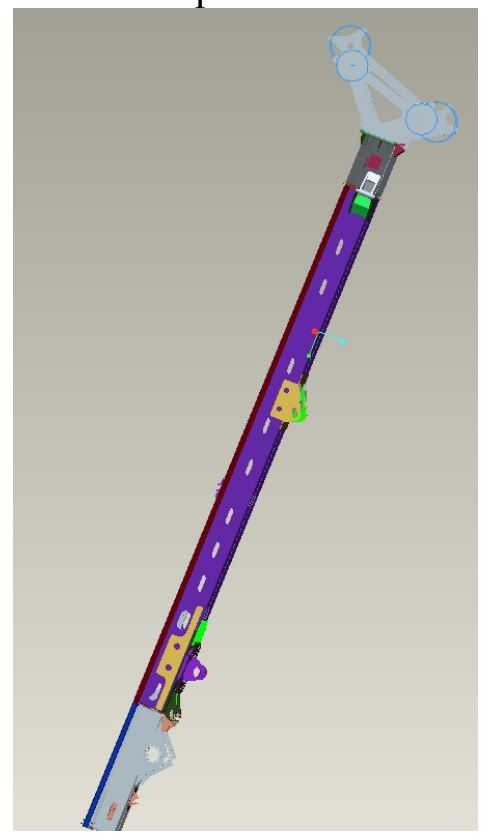

Fig. 2 The mast of rig

The main body of mast of special rotary drilling rig for transmission line is $11400 \mathrm{~mm}$ length. The section size of mast is $600 \mathrm{mmX} 500 \mathrm{~mm}$, the side rake range is $\pm 4^{\circ}$, the forward rake range is $0^{\circ}-5^{\circ}$, backward rake range is $0^{\circ}-15^{\circ}$ and the overall weight is $4300 \mathrm{~kg}$.

\section{Analysis of Working Condition}

The mast have many working conditions, such as lifting mast, lifting drill, drilling, soil dumping, transposition, and so on. The lifting mast, lifting drill and drilling are the more important working conditions of the mast [3]. So the stress analysis of the lifting drill condition and drilling condition are carried out here.

(1)Under the lifting drill condition, the mast mainly loads the lifting force of the main winch $160 \mathrm{KN}$ and the lifting force of pull-down cylinder $160 \mathrm{KN}$ in the maximum lifting force state of the main winch.

The pin hole of stopping cylinder and the large disc are imposed fixed constraint. 
(2)Under the drilling condition, the mast mainly loads the torque of rotary drive $200 \mathrm{KN} . \mathrm{m}$ and pressure of pull-down cylinder $120 \mathrm{KN}$ when the drill tool is pressurizing and rotary cutting in the earth. The pin hole of stopping cylinder and the large disc are imposed fixed constraint.

\section{FEM Calculation}

According to design drawings of special rotary drilling rig for transmission line XRL180L, the 3D entity models of top mast, mid mast, lower mast and other components are established with finite element software ANSYS. The bottom-up assembly method is used to finish the 3D solid model assembly $[4,5]$.

According to lifting drill condition and drilling condition, the finite element analysis of the mast is carried out.

(1)Lifting drill condition

The stress and displacement distribution of the mast as shown below:

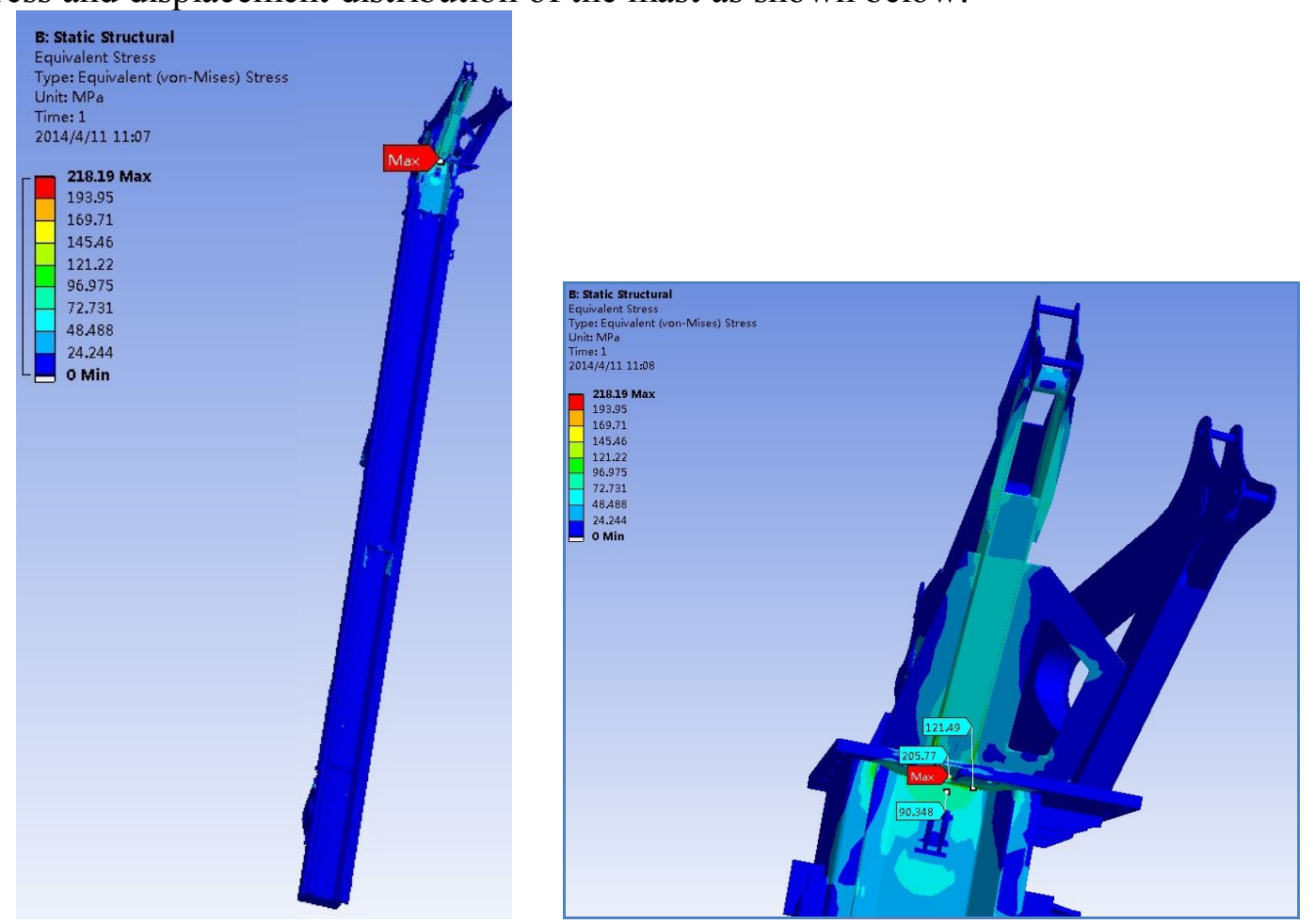

Fig. 3 The stress distribution of the mast in maximum lifting force state

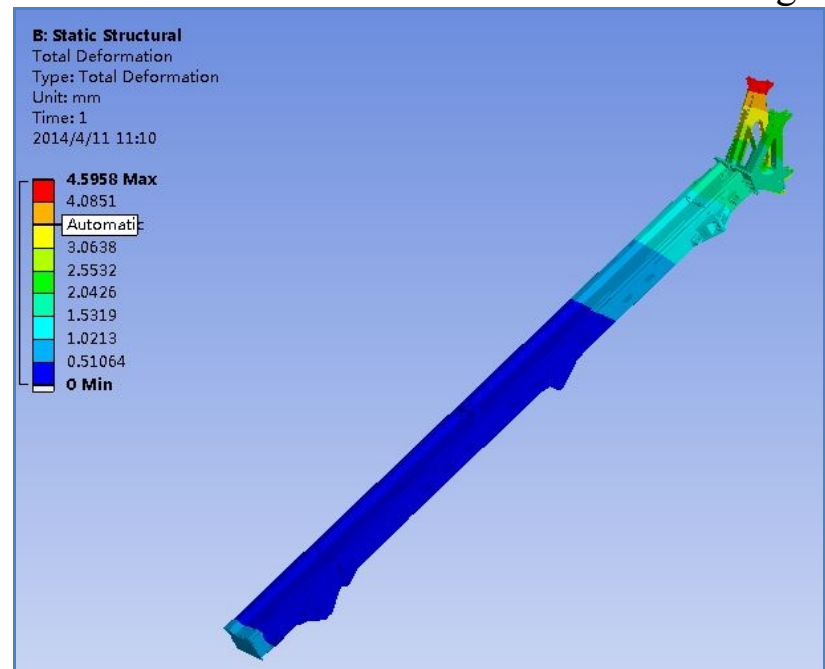

Fig. 4 The displacement distribution of the mast in maximum lifting force state

Through the above stress state simulation of the mast when the lifting force of main winch is the maximum, the following conclusions can be drawn : 
The displacement maximum of mast is located in the vertical plate of main winch in the goose head, and this displacement is $4.5 \mathrm{~mm}$ which conforms to the construction conditions of rotary drilling rig.

The stress maximum of mast is located in the plane between the top mast and goose head, and the stress maximum is $218 \mathrm{MPa}$. The material is steel Q390A and the strength of this material is satisfied with the requirements.

To view the mast as a whole, the stress of mast is less than the yield strength, and stress of the most regions is far less than the yield strength of the material under this condition.

(2) Drilling condition

The stress and displacement distribution of the mast as shown below:

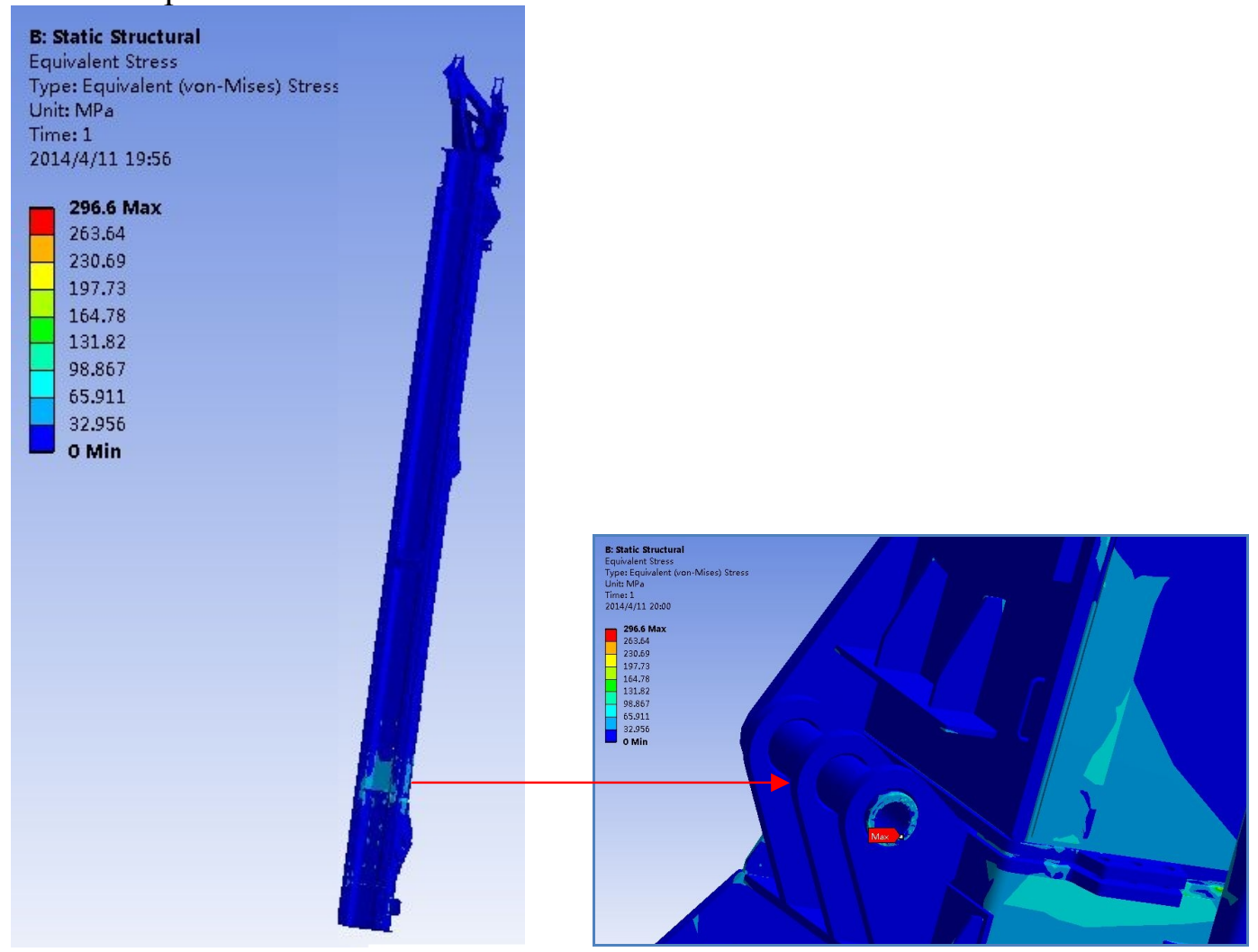

Fig. 5 The stress distribution of the mast in maximum torsion

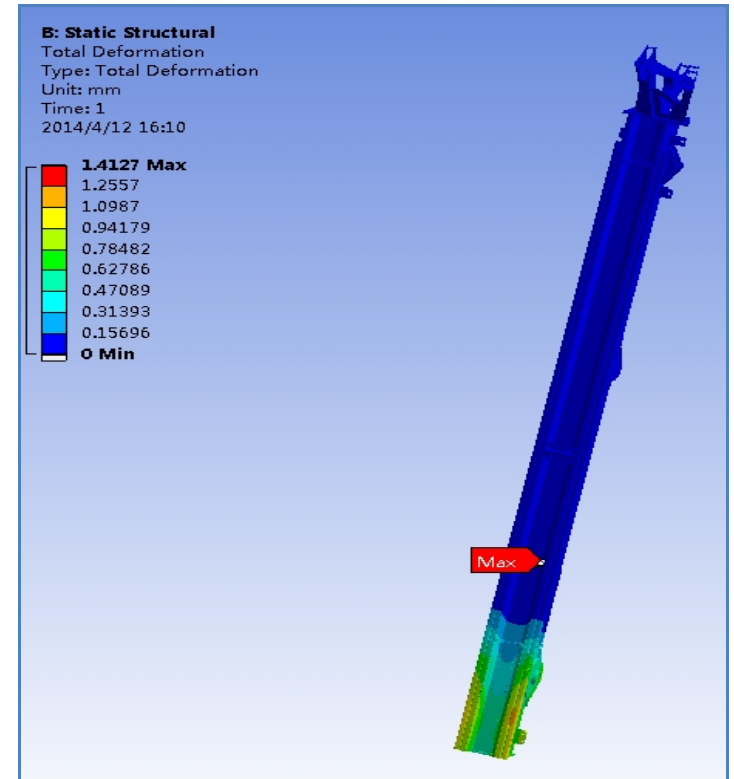

Fig. 6 The displacement distribution of the mast in maximum torsion

The stress analysis of the mast is shown in figure 5 when output of rotary torque is the maximum.

The maximum stress of mast is located in the connection axle hole between mid mast and low mast, the stress value is $296 \mathrm{MPa}$ and the materials is steel 35 that meet using requirements. 
The displacement maximum of mast is located in plug weld of mid mast, $1.4 \mathrm{~mm}$ which meets working requirements.

To view the mast as a whole, the stress of mast is less than the yield strength, and stress of the most regions is far less than the yield strength of the material under this condition.

\section{Summary}

In this paper, according to the mast structure characteristics and force condition, the stress distribution of the mast is obtained based on the simplified finite element model of mast, and the static strength under lifting drill and drilling conditions is analyzed.

It's confirmed that the connection plane between top mast and goose head, the connection axle hole and several other positions are the dangerous parts of the mast. The other parts of mast body are safe, where the stress is far less than the yield strength. These conclusions provide an important theoretical basis for the following finite element optimization design of the mast.

\section{References}

[1] Zhang Qijun, Zhang Zhonghai, Chen Yitian, Zheng Hua. Discussion of drilling rig structure[J]. Road Machinery \& Construction Mechanization. 2004(10):37-41.

[2] LIU Wei. Development of thread-type borer and its application[J]. Cconstruction Mechanization. 2004(11):16-18.

[3] KANG Huimei, HE Qinghua, XIE Songyue , ZHU Jian-xin. Mechanics analysis of rotary drilling rig under drilling-bucket-lifting conditions. Engineering Mechanics, 27(10):214-218 2010.

[4] Khuief Y A, AL-NASER H. Finite element dynamic analysis of drill strings[J].Finite Elements in Analysis and Design,2005(41):1270-1288 .

[5] GONG Jin, WU Yonghong, KANG Huimei, JIANG Yong-zheng. Structural strength analysis on drilling mast of rotary drilling rig based on SolidWorks and ANSYS[J]. Modern Manufacturing Engineering 2010(8):136-140. 